Research Paper, part of a Special Feature on Quantifying Human-related Mortality of Birds in Canada

\title{
Estimated Mortality of Selected Migratory Bird Species from Mowing and Other Mechanical Operations in Canadian Agriculture
}

\section{Estimation de la mortalité aviaire par le fauchage et d'autres opérations mécanisées utilisées en agriculture au Canada}

\author{
Joerg Tews ${ }^{1}$, Daniel G. Bert ${ }^{2}$ and Pierre Mineau ${ }^{2}$
}

\begin{abstract}
Mechanical operations such as mowing, tilling, seeding, and harvesting are well-known sources of direct avian mortality in agricultural fields. However, there are currently no mortality rate estimates available for any species group or larger jurisdiction. Even reviews of sources of mortality in birds have failed to address mechanical disturbance in farm fields. To overcome this information gap we provide estimates of total mortality rates by mechanical operations for five selected species across Canada. In our step-by-step modeling approach we (i) quantified the amount of various types of agricultural land in each Bird Conservation Region (BCR) in Canada, (ii) estimated population densities by region and agricultural habitat type for each selected species, (iii) estimated the average timing of mechanical agricultural activities, egg laying, and fledging, (iv) and used these values and additional demographical parameters to derive estimates of total mortality by species within each BCR. Based on our calculations the total annual estimated incidental take of young ranged from 138,000 for Horned Lark (Eremophila alpestris) to as much as $\sim 941,000$ for Savannah Sparrow (Passerculus sandwichensis). Net losses to the fall flight of birds, i.e., those birds that would have fledged successfully in the absence of mechanical disturbance, were, for example $\sim 321,000$ for Bobolink (Dolichonyx oryzivorus) and $\sim 483,000$ for Savannah Sparrow. Although our estimates are subject to an unknown degree of uncertainty, this assessment is a very important first step because it provides a broad estimate of incidental take for a set of species that may be particularly vulnerable to mechanical operations and a starting point for future refinements of model parameters if and when they become available.
\end{abstract}

RÉSUMÉ. Les opérations mécanisées telles que le fauchage, le labourage, l'ensemencement et la récolte sont des sources bien connues de mortalité aviaire directe dans les champs agricoles. Toutefois, il n'existe actuellement aucune estimation du taux de mortalité pour tout groupe d'oiseaux ou grande région. Même les revues de littérature visant à dresser les sources de mortalité d'oiseaux n'ont pas examiné le dérangement attribué aux opérations mécanisées dans les champs agricoles. Pour pallier ce manque d'information, nous présentons des estimations du taux de mortalité totale par les opérations mécanisées chez cinq espèces dans l'ensemble du Canada. Notre approche de modélisation par étape nous a permis de : 1) quantifier la superficie de divers types de milieux agricoles dans chaque région de conservation des oiseaux (RCO) au Canada; 2) estimer les densités de population par RCO et type de milieux agricoles pour chacune des cinq espèces; 3 ) estimer la période moyenne des activités agricoles mécanisées, de la ponte et de l'envol de jeunes; et 4) utiliser ces valeurs et d'autres paramètres démographiques pour calculer des estimations de la mortalité totale par espèce dans chaque RCO. Selon nos calculs, la prise accessoire annuelle de jeunes s'échelonnait d' 138 000 pour l'Alouette hausse-col (Eremophila alpestris) à autant qu' 941 000 pour le Bruant des prés (Passerculus sandwichensis). La perte nette d'oiseaux dans la volée d'automne, c'est-à-dire les oiseaux qui auraient pris leur envol avec succès en l'absence de dérangement attribué aux opérations mécanisées, était de l'ordre d' 321 000 pour le Goglu des prés (Dolichonyx oryzivorus) et d' 483 000 pour le Bruant des prés, par exemple. Même si nos estimations comportent un certain degré d'incertitude, cette évaluation représente une première étape fort importante, d'abord parce qu'elle fournit une estimation globale de la prise accessoire chez un groupe d'espèces qui peut être particulièrement vulnérable aux opérations mécanisées, puis parce qu'elle fait office de point de départ pour d'éventuelles améliorations aux paramètres des modèles, si et quand celles-ci seront disponibles.

Key Words: agricultural management; avian mortality; Bobolink; Grasshopper Sparrow; grassland birds; grassland management; mowing

${ }^{1}$ Noreca Consulting Inc, ${ }^{2}$ Science and Technology Branch, Environment Canada

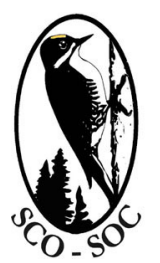

Sponsored by the Society of Canadian Ornithologists and Bird Studies Canada Parrainée par la Société des ornithologistes du Canada et Études d'oiseaux Canada

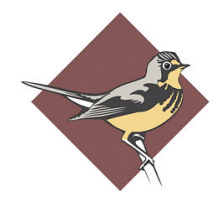

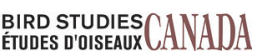




\section{INTRODUCTION}

Agricultural practices over the last century have been marked by a shift from small diversified systems to large, monoculture operations (Hannah et al. 1995, Tilman et al. 2001). Effects of this change are extensive, including increased use of pesticides (Freemark and Kirk 2001), decreased rates of crop rotation (Roth et al. 2005), loss of riparian zones (Jobin et al. 2004), and an increased reliance on mechanical activities for agricultural management (Askins et al. 2007). Mechanical agricultural activities such as mowing, tilling, seeding, and harvesting are known sources of direct avian mortality in agricultural fields (Bollinger et al. 1990, Nocera et al. 2005) through the destruction of nests and death of incubating individuals (e.g., Shustack et al. 2010). The combination of these activities has resulted in a loss of biodiversity generally (McLaughlin and Mineau 1995) and a loss of viable habitat for birds more specifically (Mineau and McLaughlin 1996). This is believed to be part of the reason for declines in breeding populations of many bird species associated with agriculture throughout North America (Faaborg et al. 2010, Downes et al. 2011).

Grassland birds have been most dramatically affected: based on Breeding Bird Survey (BBS) data from 1980 to 1999, 15 of 25 species of grassland birds declined significantly over this period (BirdLife International 2004). The losses noted in North America (Herkert 1994, 1997, McCracken 2005, Faaborg et al. 2010) have mirrored or even exceeded farmland bird declines in the intensively farmed European landscapes (Bradbury et al. 2000, Chamberlain et al. 2000). For example, the Bobolink (Dolichonyx oryzivorus) declined $80 \%$ between 1968-2006 (Downes et al. 2011); the same time period saw a $78 \%$ decline in Grasshopper Sparrows (Ammodramus savannarum), with a $25 \%$ loss among Savannah Sparrow (Passerculus sandwichensis) populations (Downes et al. 2011).

Although careful management of agricultural landscapes can mitigate some of the impacts of agriculture on birds (e.g., Nocera et al. 2007, Norment et al. 2010) the current extent of the incidental take resulting from mechanically induced operations remains largely unknown. Mowing is likely the most important mechanical disturbance that results in bird mortality; many species nest in cultivated forage fields (tame grass) where mowing operations take place repeatedly and at a time when there is a reasonable chance of overlap with nesting. Habitat disturbance is often severe and can result in complete nest destruction (Calverley and Sankowski 1995, Perlut et al. 2006). In addition, abandonment and predation rates can be higher after haying (Perrit and Best 1989, Bollinger et al. 1990, Calverley and Sankowski 1995, Perlut et al. 2006). Nest success can also be affected by other agricultural mechanical activities such as seeding, tillage, and harvest. However, tillage and seeding operations typically occur early when only a few species have established nests; therefore fewer species are affected. Harvesting of fruit, vegetable, and grain crops often occurs later in the season, when the majority of young have left the nest.

A few selected bird species have been studied in the context of incidental take because of mowing and other mechanical operations. For example in Europe, Winchat (Saxicola rubetra; Müller et al. 2005, Grüebler et al. 2008, 2012) and Corncrake (Crex crex) populations (Green 1996) have experienced significant declines because of mowing-induced nest destruction. In North America, the Bobolink is the best studied species. For example, a New York study by Bollinger et al. (1990) across a variety of agricultural land types found an average mortality rate of $94 \%$ in young (eggs and nestlings combined), of which $51 \%$ was attributed to hay-cropping, $24 \%$ to abandonment after mowing, $10 \%$ to raking and/or baling, and $9 \%$ to predation. Similarly, Perlut et al. (2006) found evidence of a relationship between the timing of mowing and nest success rates, where differences in the number of eggs and fledglings per year per female depended on the timing of the cut. For Savannah Sparrow, Perlut et al. (2006) reported a $50 \%$ loss of young in early-hayed fields as a result of mowing, and a $45 \%$ loss in midseason hayed fields. They concluded that grassland management was the strongest factor affecting nest success and daily nest survival rates. For Grasshopper Sparrows, Giuliano and Daves (2002) reported 8.5\% of failed nests were destroyed directly as a result of mowing in fields of cool season grasses, while $67 \%$ failed due to predation. In a study of Vesper Sparrows (Pooecetes gramineus), McMaster et al. (2005) observed 39\% egg loss in both years of their study in southern Saskatchewan, and a $36 \%$ and $42 \%$ loss of hatched young in the first and second years, respectively. The paper did not expand on specific causes of mortality, but noted that the portion of loss due to haying was minimal because of wet weather causing a delay in mowing in both years. An estimated $25-30 \%$ of total nests would have been vulnerable if mowing had occurred on 7 July (as opposed to the 17 and 18 July median cut dates reported). Perrit and Best (1989) drew similar weather-related conclusions from their study in corn and soybean fields in Iowa. They found that nest success in a wet season was significantly higher than that in a dry season, and suggested that this difference was due primarily to earlier (by $\sim 30$ days) and more frequent field cultivation in dry years.

There are relatively few published studies that attempt to estimate the incidental take of birds resulting from agricultural activities. Of these, the majority focus on a single species (for example, Green et al. 1997a, $b$ ). To our knowledge, no attempts have been made to extend estimates of incidental take resulting from mechanical operations from the field scale to larger spatial scales and throughout agricultural lands in Canada. Even reviews of sources of mortality in birds (for example, Banks 1979, Erickson et al. 2005) have failed to address mechanical disturbance in farm fields. To overcome this information gap, we (i) quantified the amount of various types 
Table 1. Migratory bird species and their agricultural habitat scores ranked by cumulative National Agri-Environmental Health Analysis and Reporting Program (NAHARP) habitat scores. For each species the score is calculated based on the NAHARP habitat matrix database where only categories 0.75 and 1.0 were retained. A high cumulative score identifies species highly associated with agricultural habitat types and that are widely distributed across all eco-regions in Canada. A high average score identifies species highly associated with agricultural habitat types independent of regional distribution.

\begin{tabular}{|c|c|c|c|c|}
\hline Common Name & Scientific Name & Preferred habitats and identified risk. & $\begin{array}{l}\text { Cumulative Habitat } \\
\text { Score }\end{array}$ & $\begin{array}{l}\text { Average Habitat } \\
\text { Score }\end{array}$ \\
\hline Horned Lark & Eremophila alpestris & $\begin{array}{l}\text { Bare ground, early nesting. Most at risk from } \\
\text { ploughing, seeding, and early fallow tillage. }\end{array}$ & 48.25 & 0.91 \\
\hline Vesper Sparrow & Pooecetes gramineus & $\begin{array}{l}\text { Mix of open pasture and cultivated fields } \\
\text { especially if low till. At risk from any } \\
\text { operation. }\end{array}$ & 40.75 & 0.77 \\
\hline Bobolink & Dolichonyx oryzivorus & $\begin{array}{l}\text { Selects denser, taller hay-fields and pasture, } \\
\text { seldom selects cropland. Most at risk from } \\
\text { haying operations. }\end{array}$ & 22.25 & 0.82 \\
\hline Savannah Sparrow & Passerculus sandwichensis & $\begin{array}{l}\text { Selects wide range of hay-fields and pasture, } \\
\text { seldom selects cropland. Most at risk from } \\
\text { haying operations. }\end{array}$ & 20.50 & 0.85 \\
\hline Clay-colored Sparrow & Spizella pallida & $\begin{array}{l}\text { Edge species. Prefers grass \& shrub mix, } \\
\text { brushy pastures, some hayfields. At some risk } \\
\text { from haying. }\end{array}$ & 4.50 & 0.75 \\
\hline
\end{tabular}

of agricultural habitat for selected migratory bird species, (ii) determined relative population densities by region and agricultural habitat type, (iii) estimated the average timing of various mechanical agricultural operations, and (iv) used these values to derive estimates of total mortality by species within each region.

\section{METHODS}

\section{Species selection}

As a first step, we assembled a larger pool of species likely to be affected by mechanical operations because of their propensity to nest in forage or field crops. We were aided by a compilation of species-specific agricultural habitat 'scores' assembled by Agriculture and Agri-Food Canada in the course of the National Agri-Environmental Health Analysis and Reporting Program (NAHARP, www.agr.gc.ca/env/naharppnarsa; Appendix 1, Sheet 3). Because of the enormity of the modeling task as well as jurisdictional requirements (this work was commissioned by the Canadian Wildlife Service) we focused our analysis on five federally protected migratory songbird species that we believed to be most representative of songbirds threatened by various mechanical operations. We restricted the total number of study species to a maximum of five representative species for which breeding demographics and information on nesting densities in various habitat types across agricultural regions in Canada were sufficiently available. Our final list of candidate species was Horned Lark (Eremophila alpestris), Vesper Sparrow, Bobolink, Savannah Sparrow, and Clay-colored Sparrow (Spizella pallida; Table $1)$.

\section{Modeling approach}

For each species our modeling approach required mean population density per Bird Conservation Region (BCR; Fig. 1) and habitat type (grain/cereal, hay, fallow, and fruit/ vegetable crops). Estimated habitat amount per BCR for the four habitat categories were based on aggregated data from the 2001 NAHARP agricultural habitat census (see Appendix 1, Sheet 2). Mean population densities were estimated based on observed densities for each BCR and habitat type as reported in the literature and the Canadian Breeding Bird Census (BBC) Database (Kennedy et al. 1999), which contains breeding pair density information from hundreds of sites across Canada (see Appendix 1). Finally, population abundances for each BCR were estimated based on the product of NAHARP habitat area times the estimated population density. Thus, population sizes for each BCR reflect only estimates for agricultural habitat types that were available through the NAHARP agricultural habitat census, i.e., other habitat types such as roadsides or permanent pastures were not considered.

In addition to species' population densities, we required mean clutch size and survival rates in the absence of incidental take by agriculture (see 'Background' in Fig. 2). We assumed that any eggs or young in the field at the time of seeding (Horned Lark) or cutting (all other species) suffer 100\% mortality. For each BCR we furthermore defined (i) range of egg laying dates, given in days, (ii) intra-annual egg laying date variation, in days, (iii) possible 1st day of egg laying, (iv) possible 1st day of fledging, and (v) intra-annual fledging date variation, in days. Number of broods was assumed to be one. These data 
Fig. 1. Map of Bird Conservation Regions (BCR) in southern Canada. Agricultural regions are covered by: $5=$ Northern Pacific Rainforest, $6=$ Boreal Taiga Plains, $8=$ Boreal Softwood Shield, $9=$ Great Basin, $10=$ Northern Rockies, 11 = Prairie Potholes, $12=$ Boreal Hardwood Transition, 13 = Lower Great Lakes/St. Lawrence Plain, $14=$ Atlantic Northern Forest (Map source: Bird Studies Canada 2013, http://www.birdscanada.org).

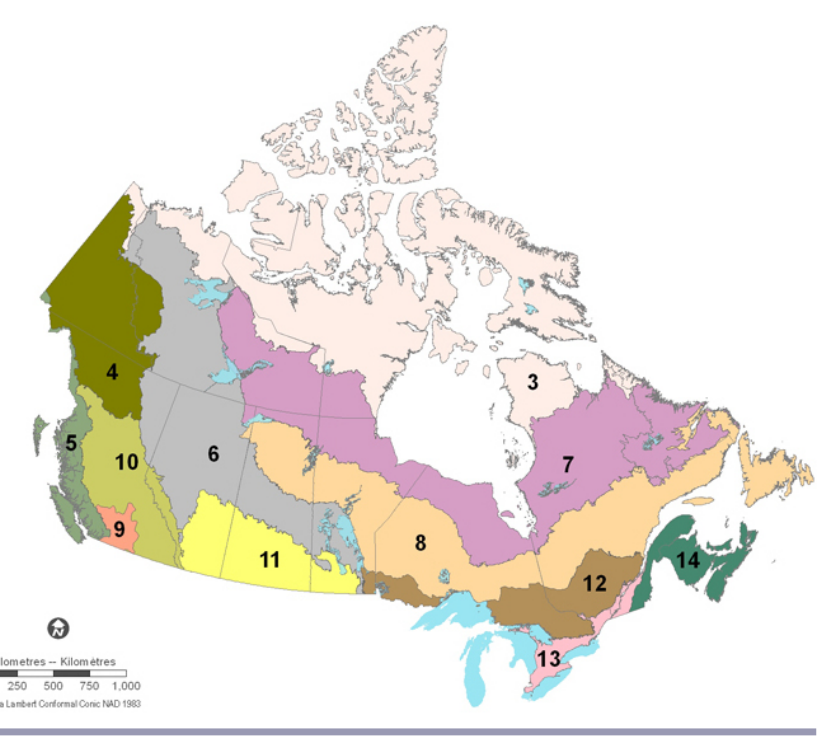

were obtained from reviewing the literature and from an extensive database we developed prior to this analysis (see Appendix 1, Sheet 1), or were based on expert opinion or our own assumptions. Based on these data we calculated total adult population size and number of eggs per BCR and habitat type that are potentially subject to annual loss from mechanical farming operations.

To verify our estimated population abundances for each focal species in each agriculture-dominated BCR across Canada we did a comparison with the Partners in Flight (PIF) online estimates based on the BBS database (http://rmbo.org/pif db/ laped); Blancher et al. 2007). If our estimated abundance per BCR was higher than the PIF/BBS BCR estimate (note that the BBS abundance estimates also include nonagricultural habitat which we did take into account), we lowered the population densities by using density estimates from the lower end of reported ranges, if available (details of the various chosen rates for all bird species are provided in Appendix 1, Sheet 4).

Nesting periods are typically long for most species. For example, in Bobolinks egg laying typically occurs over a 41 day period, with a 10-13 day incubation period, followed by 10-13 days when young are in the nest prior to fledging (Bollinger et al. 1990, Winter et al. 2004). Thus, the earliest
Fig. 2. Simplified flow chart for calculating incidental take.

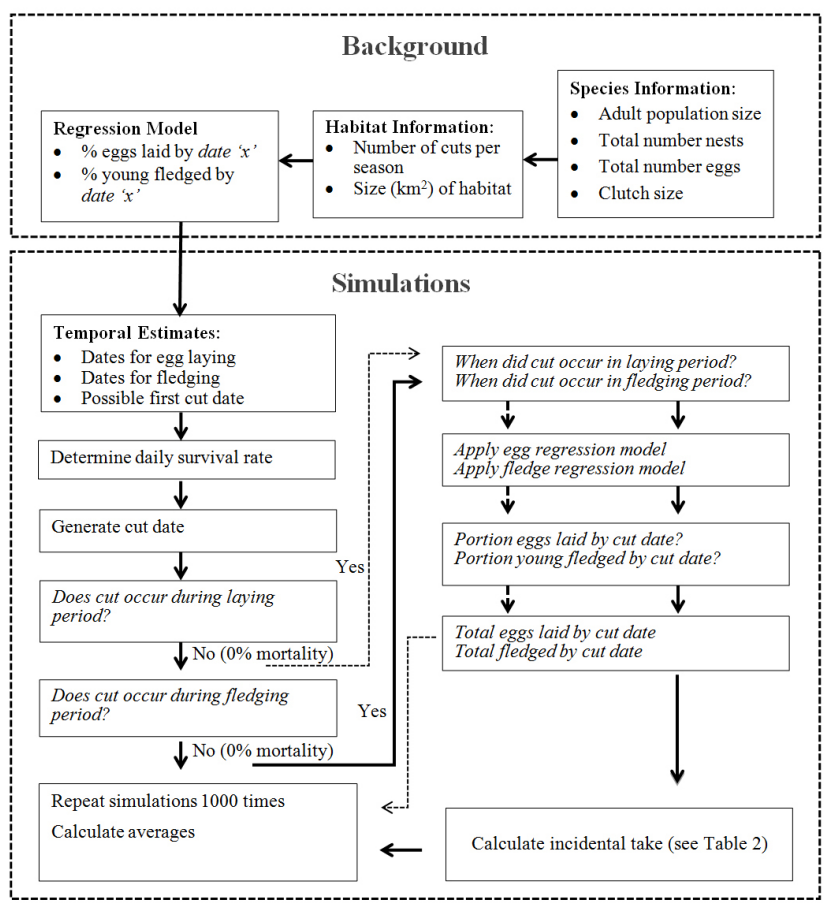

laid eggs could produce fledged young before the laying period ends (Fig. 3). Because of this variation as well as variation in regional agricultural operations we ran 1000 stochastic simulations per species, BCR and habitat type combination, varying dates for mechanical operations (Poisson distributed), as well as dates for egg laying and fledging (random draw) within ranges reported in the literature (see Fig. 2 and Appendix 1). Selected date ranges for mechanical operations varied from as early as 4 April to 30 May for planting/seeding (applied to the Horned lark model), to 15 May to 31 July for haying (potentially affecting Bobolink, Clay-colored Sparrow, Vesper Sparrow; see Appendix 1, Sheet 4). The actual day of the mechanical operation was determined relative to the first egg laying date because of an assumed correlation based on weather dependence within a given year. To account for this correlation, the possible first egg laying dates were divided into thirds; if the randomly selected first day of egg laying was in the first third of possible egg laying dates, the mechanical operation was randomly selected within the first third as well.

For each simulated mechanical operation (SMO) the percentage of eggs laid by the date that the SMO took place (hereafter "cut date" whether seeding or actual cutting) was determined using a regression model (see Appendix 1 and 
Table 2. Overview of all model parameters and calculation steps.

\begin{tabular}{|c|c|}
\hline Parameter & Description \\
\hline$A$ & Area $\left(\mathrm{km}^{2}\right)$ \\
\hline$D$ & Population density (ind. $/ \mathrm{km}^{2}$ ) \\
\hline $\mathrm{Cl}$ & Clutch size \\
\hline$E_{\text {ugr }}$ & Egg date variation \\
\hline$E_{\text {first }}^{\text {var }}$ & Earliest first egg laying date \\
\hline$E_{\text {first_min }}^{\text {first }}$ & Latest first egg laying date \\
\hline$E_{\text {first_max }}^{\text {first }}$ & First egg laying date (random) between $E_{\text {first min }}$ and $E_{\text {first } \max }$ \\
\hline$E_{\text {last }}^{\text {flist }}$ & Last egg laying date: $E_{\text {first }}+E_{\text {var }} \quad$ first $\_$min \\
\hline$F_{\text {var }}^{\text {last }}$ & Fledging date variation ${ }^{\text {first }}$ var \\
\hline$N^{v a r}$ & Mean incubation and nesting period \\
\hline$F_{\text {first }}$ & First fledging date: $E_{\text {first }}+N$ \\
\hline$F_{\text {last }}^{\text {first }}$ & Last fledging date: $F_{\text {first }}^{\text {firt }}+F_{v a r}$ \\
\hline$C_{\min }^{\text {last }}$ & Earliest cut date first var \\
\hline$C_{\max }^{m}$ & Latest cut date \\
\hline$C^{\max }$ & Cut date (random) between $C_{\min }$ and $C_{\max }$ \\
\hline$S_{d}$ & Daily survival rate (DSR) \\
\hline$E_{\text {days in }}$ & Days into egg laying: $C-E_{\text {first }}$ \\
\hline$P_{e g g}^{a_{y y} s_{-i n}}$ & $\begin{array}{l}\text { Regression model to predict percent eggs laid by cut date: } r_{1}+\left(\mathrm{r}_{2} * \mathrm{E}_{\text {days_in }}\right)-\left(\mathrm{r}_{3} * \mathrm{E}_{\text {days_in }}{ }^{2}\right) \text {; parameters } r_{1} \text { to } r_{3} \text { species- } \\
\text { specific (see Appendix) }\end{array}$ \\
\hline$E_{\text {total }}$ & Total number of eggs: $\left(\left(D^{*} A\right) / 2\right)^{*} C l$ \\
\hline$E_{\text {laid cut }}^{\text {total }}$ & Eggs laid by cut date: $P_{e g g} * \mathrm{E}_{\text {total }}$ \\
\hline$F_{\text {days in }}$ & Days into fledging: $C-F_{\text {first }}$ \\
\hline$P_{\text {fledge }}$ & $\begin{array}{l}\text { Regression model to predict percent fledged by cut date: }\left(\left(r_{1}+\left(r_{2}^{*} F_{\text {days_in }}\right)-\left(r_{3}^{*} F_{\text {days_in }}{ }^{2}\right)\right) / 100\right)-1 \text {; parameters } r_{1} \text { to } r_{3} \\
\text { species-specific (see Appendix) }\end{array}$ \\
\hline$M_{\text {y__lost }}$ & Number of young in the nest for the cut, no natural mortality: $E_{\text {laid_cut }} *\left(P_{\text {egg }}-\mathrm{P}_{\text {fledge }}\right)$ \\
\hline$D_{\text {nest_day }}$ & Median nest day: $(N-1) /$ \\
\hline$S_{m}$ & Median survival rate: $S_{d}^{\text {Dnest_day }}$ \\
\hline$M_{y g_{-} \text {lost_net }}$ & $\begin{array}{l}\text { Gross incidental take or total number of young (egg and prefledging stage) killed directly by mechanical farming } \\
\text { operations, i.e. number of young in the nest at the cut date: } S_{m} * M_{y g} \text { lost }\end{array}$ \\
\hline$S_{n}$ & 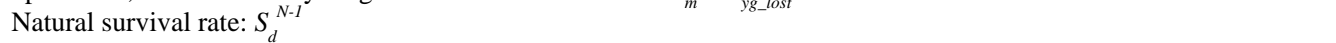 \\
\hline$M_{y g \_a d d}^{n}$ & $\begin{array}{l}\text { The number of additional young lost because of mechanical operations that would have been expected to survive in the } \\
\text { absence of the cut: } M\end{array}$ \\
\hline
\end{tabular}

Fig. 3. Generalized annual patterns of timing of egg-laying and fledging in Bobolinks (Dolichonyx oryzivorus), following Winter et al. (2004) and Bollinger et al. (1990), respectively. As indicated, overlap occurs when young hatching from the earliest nests will fledge before all of the eggs have been laid in the population.

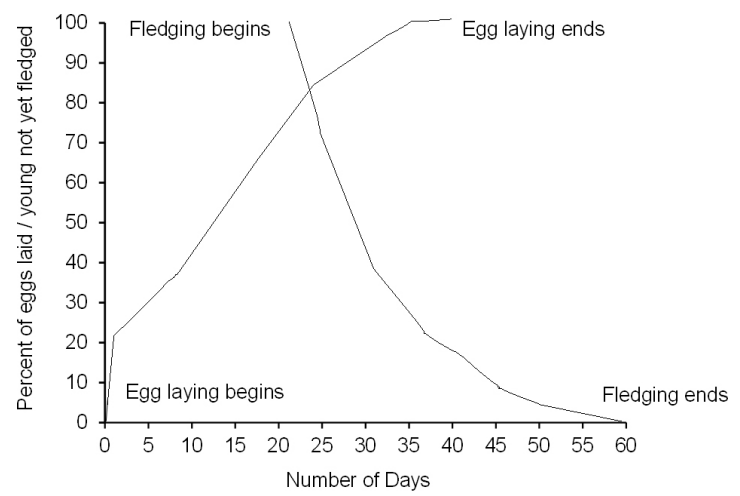

Table 2). The model output was then used in conjunction with the total number of eggs, derived from population density estimates and mean clutch size, to calculate the number of eggs laid by the cut date. The number of young already fledged by the cut date was calculated using the same approach, and this value was subtracted from the number of eggs laid to determine the number of young that would be present for the SMO (Table 2).

The daily survival rate (DSR), randomly selected from the range reported in the literature assuming a discrete uniform distribution, was then used in conjunction with the incubation and prefledging period (days) to determine how many of the young potentially present on the cut date, i.e., in the absence of mortality, would be expected to have died of natural causes by this date (Table 2). This "individual" approach was selected over a "whole-nest" approach given that DSR relates to each of the young independently, and could then be used to produce an estimate of the number of young present for the SMO.

The estimated number of young present for the SMO is equivalent to the total incidental take given that the model assumes that $100 \%$ of the young, present when the cut, tillage, or seeding operation occurs, will die. Based on the DSR and 
the incubation and prefledging period the number of young expected to die of natural causes in the absence of the SMO was calculated. This value was used to derive the number of young that were killed by the SMO that would otherwise be expected to survive ("additional young lost" hereafter), i.e., the overall increase in mortality resulting from mechanical operations (Table 2).

In summary, we estimated the annual number of young killed (egg and prefledging stage) as a result of mowing, seeding, and tillage operations for the five selected species in each BCR, and for each relevant agricultural habitat type category. These estimates needed to be calculated at that level because of variations in agricultural practices across habitat types and regions as well as variations in bird population density across BCRs and habitat types.

\section{Sensitivity analysis}

Performing a sensitivity analysis for all species, BCR and habitat type combinations would have resulted in too many model scenarios. We therefore selected a representative parameterization to analyze the importance of relevant model parameters. We then varied each model parameter in turn while keeping all other parameters constant and using young lost at cut time as the model output $\left(M_{\text {yg_lost_net }} ;\right.$ Fig, 4). All simulations were replicated 1000 times.

\section{Modeling assumptions specific to the various agricultural operations}

\section{Hay}

A positive association between timing of breeding and cut dates occurs because favorable weather results in both earlier egg laying and hay cutting dates. As such, randomly generated first egg laying days that are within the first third of the possible dates have cut dates that fall within the first third of possible dates for haying. Model output associated with this habitat type is relevant only for the first cut; to avoid adding another layer of complexity we did not consider subsequent SMO events in addition to that of the first cut.

\section{Fallow}

As with hay habitat, if the random number generated for first day of egg-laying was in the first third of possible dates, then the tillage operation was presumed to occur in the first third of possible dates, e.g., mid-June to mid-July. Mortality predictions associated with fallow land were simulated for only the first mechanical tillage operation; if more than one tillage operation occurs in a given year any related mortality would be in addition to the first till.

Fruit and vegetable crops

Fruit and vegetable crops are used as primary habitat only by Savannah Sparrows and Vesper Sparrows in BCR 8, 12, 13,
Fig. 4. Results of the generic sensitivity analysis. Lines show relative $\%$ change for each parameter (x-axis) vs. relative \% change in young lost at cut $\left(M_{y g_{\_} \text {lost_net }} ;\right.$ averaged over 1000 replicate runs): daily survival rate (Sd), first cut date (Cmin), first egg-laying date (Efirst), length of incubation and nesting period $(\mathrm{N})$, population density (D), clutch size $(\mathrm{Cl})$. Default parameterizations were: $\mathrm{Sd}=0.95$, Cmin $=140$, Efirst $=140, \mathrm{~N}=20, \mathrm{D}=20 / \mathrm{km}^{2}, \mathrm{Cl}=5$, egg regression model (to calculate \% eggs laid at day $\mathrm{x}$ ): $0.10349+(0.04193 *$ Edays_in $)-\left(0.00047 *\right.$ Edays_in $\left.{ }^{2}\right)$, fledge regression model (to calculate \% fledged at day $\mathrm{x}$ ): $((98.39757+(5.88381 *$ Fdays_in $)-(0.08724 *$

Fdays_in²))/100) - 1 (see Table 2 for calculation details).

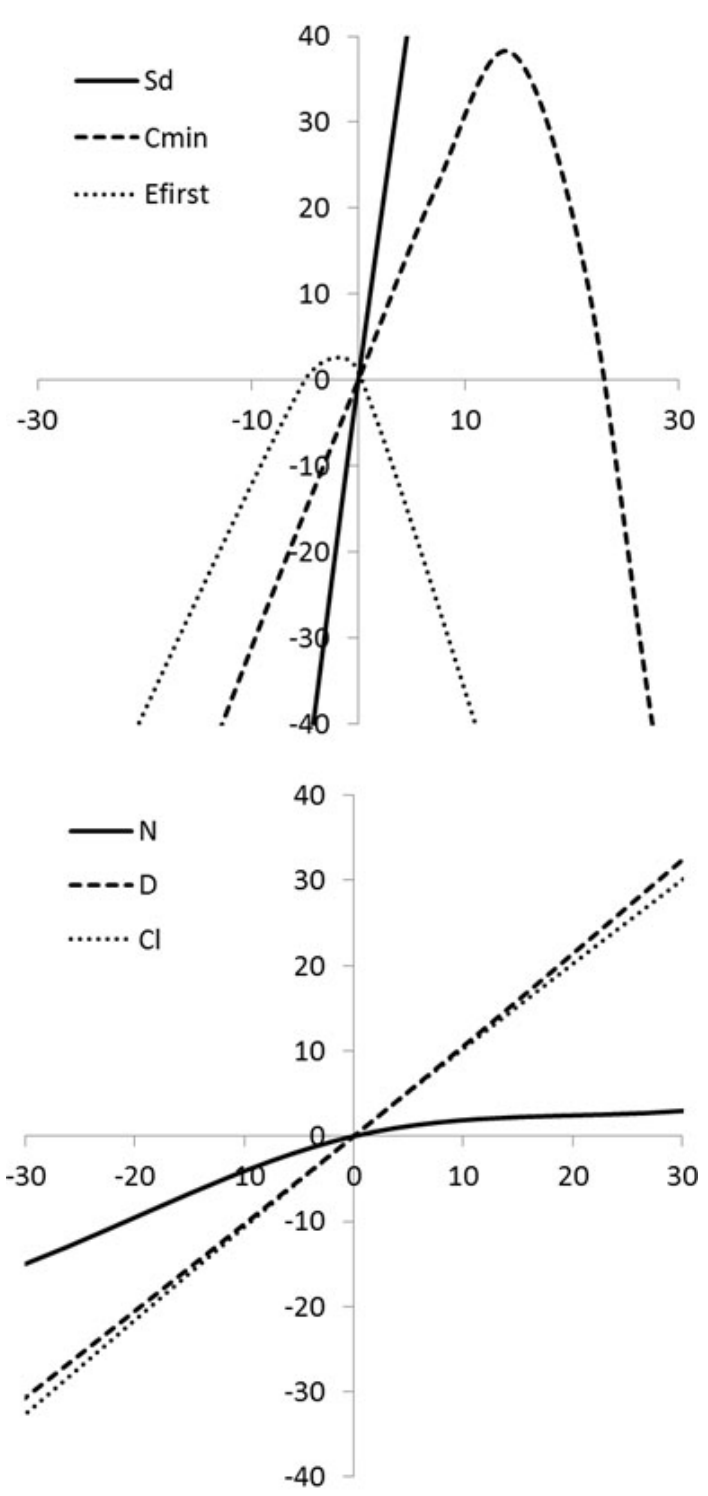


and 14 (see Appendix 1). There is a wide variety of cultivation practices represented in this habitat type. Each species of fruit, berries, and vegetables has its own agricultural regime; therefore, it is assumed that variability in this habitat is more apparent within years based on cultivated species than between years based on weather. Because of this, one-third of the simulations were from each third of potential first egg laying dates, while the "cut date," which here can refer to any mechanical agricultural regime including, e.g., planting, tillage, or harvest, varies between early April and late September with no covariation. As with other habitat types, estimated mortality was for one agricultural-related event only.

\section{Cereal crops}

Grains and cereals are typically planted in the spring and harvested in August and September (fall planting of winter cereals is not considered here). Given this, there will generally be two distinct periods of agricultural activity that could cause incidental mortality: spring planting and summer harvest.

\section{RESULTS}

\section{Sensitivity analysis}

The results from the sensitivity analysis indicate that relative changes in the daily survival rate $\left(S_{d}\right)$ had the strongest effect on changes in the number of additional young lost by mechanical operations. Sensitivity to $\left(S_{d}\right)$ was expected to be greater than to other parameters given that final estimates of incidental mortality due to agricultural operations is intrinsically linked with the number of young present for, and therefore killed by, the agricultural operation. Clutch size $(\mathrm{Cl})$, population density $(D)$, and changes in the daily survival rate $\left(S_{d}\right)$ influence the total number of young present, and thus lost following the mechanical operations, in a linear fashion. The nearly identical sensitivity of model output to changes in population density and clutch size were expected because these parameters were used together with the area of habitat in each BCR to determine the number of eggs laid, which was the parameter ultimately used in the model's calculations.

However, a relative change in first cut date $\left(C_{\min }\right)$, first egg laying date $\left(\mathrm{E}_{\text {first }}\right)$, and to a lesser extent, the length of the incubation and nesting period $(N)$, showed a different pattern because all three model parameters influence the nonlinear regression models that predict the percentage of eggs laid or young fledged when the mechanical operation occurs. Here, the most influential nonlinear parameter was the first cut date $\left(C_{\text {min }}\right)$. If the cut date occurs relatively early (not all nesting has started yet) or late (most of the young are fledged), the number of young lost following the mechanical operations is lower. These results, i.e., the relative importance of all model parameters, were consistent for all regression models used in the calculations.

\section{Incidental kill rates}

For Bobolinks the total estimated number of young annually killed by mechanical farming operations varied from $\sim 1,400$ in BCR 9 to 289,000 birds in BCR 13 (Table 3). The number of additional young (egg and prefledging stage) killed by mechanical operations that would be expected to live in the absence of these operations ranged from 735 to $\sim 154,000$ for the same two BCRs. For Savannah Sparrow these estimates were $\sim 4,000$ and $\sim 372,000$ for total number of young killed and $\sim 2,500$ and $\sim 188,000$ for additional young killed, respectively (Table 3 ). In terms of total number of young killed that would be expected to live in the absence of operations, Horned Lark was the species least prone to be killed by farming operations among our selected species. Coefficients of Variation (CV), averaged across all habitat types for a given $\mathrm{BCR}$, were relatively high for SMO regimes where the first and last cut dates were many weeks apart and the simulated cut may occur before egg-laying, or after fledging, resulting in a large variation of incidental kill rates among individual simulation runs (see Table 3).

Based on our calculations and simulations for five selected species across all BCRs and agricultural habitat types in Canada the total annual estimated incidental take of young ranged from $\sim 61,000$ for Vesper Sparrow to as much as $\sim 667,000$ for Bobolink (Table 3). Additional young lost, i.e., those birds that would have fledged successfully in the absence of mechanical disturbance, were, $\sim 321,000$ for Bobolink, 483,000 for Savannah Sparrow, and $\sim 43,000$ for Horned Lark.

\section{DISCUSSION}

To our knowledge, this is the first general estimation of incidental take by mechanical agricultural operations on bird populations in Canada. On a proportional basis, the case-study species most affected by mechanical farming operations were Bobolinks (young only). These results are not surprising given the dependence of Bobolinks on hayfields for breeding (Herkert 1997). In general, we found that differences in the degree to which bird populations are subject to incidental take arise because of differences in their habitat preferences.

Although this report focuses on effects of agricultural practices on avian populations, other species may also be affected (e.g., Saumure et al. 2007, Humbert et al. 2009). Already, conversion of native grassland to agriculture has resulted in the loss of approximately $75 \%$ of the grassland habitat in the prairie provinces of Canada (Downes et al. 2011) and over $70 \%$ of the world's remaining grassland habitat is now devoted to agriculture (Hannah et al. 1995). It is clear that, even for species that can adapt to cultivated agricultural land, there are substantial risks.

The link between mechanical disturbance and avian mortality is unmistakable; in a North American study by Nocera and 
Table 3. Incidental take for five selected species and average coefficient of variation (CV) across different habitat types: BCR $=$ Bird Conservation Region (Canada); Pop $=$ abundance estimate based on this study (total area of agricultural habitat types considered * estimated population density); BBS = Breeding Bird Survey population estimate per BCR in Canada (includes also non-agricultural habitat); $M_{\text {yg_lost_net }}=$ total number of young (egg and prefledging stage) killed directly by mechanical farming operations; $M_{\text {yg add }}=$ number of additional young (egg and prefledging stage) killed by mechanical operations that would be expected to live in the absence of these operations.

\begin{tabular}{|c|c|c|c|c|c|c|c|}
\hline Species & $\mathrm{BCR}$ & Pop & BBS & $M_{v e}$ & $\mathrm{CV}(\%)$ & $M_{*}$ & $\mathrm{CV}(\%)$ \\
\hline \multicolumn{8}{|c|}{ Bobolink (Dolichonyx oryzivorus) } \\
\hline & 6 & 109,397 & 124,300 & 61,367 & 91 & 3,276 & 96 \\
\hline & 8 & 70,766 & 251,000 & 17,712 & 316 & 9,196 & 316 \\
\hline & 9 & 2,350 & 3,000 & 1,415 & 74 & 735 & 79 \\
\hline & 10 & 9,492 & 50,000 & 5,750 & 72 & 2,972 & 76 \\
\hline & 11 & 163,359 & 483,000 & 102,756 & 20 & 52,989 & 27 \\
\hline & 12 & 242,858 & $1,030,000$ & 70,733 & 271 & 36,173 & 271 \\
\hline & 13 & $1,315,551$ & $1,700,000$ & 289,556 & 843 & 154,334 & 837 \\
\hline & 14 & 253,786 & 350,000 & 117,495 & 269 & 61,068 & 278 \\
\hline & & & & 666,784 & & 320,743 & \\
\hline \multicolumn{8}{|c|}{ Savannah Sparrow (Passerculus sandwichensis) } \\
\hline & 5 & 108,956 & 158,000 & 22,095 & 43 & 11,273 & 74 \\
\hline & 6 & 102,833 & $8,097,000$ & 18,188 & 46 & 9,492 & 81 \\
\hline & 8 & 115,234 & $3,091,000$ & 25,062 & 98 & 13,349 & 135 \\
\hline & 9 & 20,212 & 140,000 & 4,492 & 43 & 2,511 & 73 \\
\hline & 10 & 81,632 & 990,000 & 17,849 & 40 & 9,707 & 71 \\
\hline & 11 & $1,143,510$ & $7,400,000$ & 266,582 & 41 & 136,272 & 80 \\
\hline & 12 & 297,123 & $1,120,000$ & 74,349 & 82 & 37,846 & 114 \\
\hline & 13 & $1,739,657$ & $1,800,000$ & 371,826 & 87 & 187,737 & 118 \\
\hline & 14 & 722,502 & 990,000 & 140,254 & 107 & 75,094 & 135 \\
\hline & & & & 940,697 & & 483,281 & \\
\hline \multicolumn{8}{|c|}{ Clay-Coloured Sparrow (Spizella pallida) } \\
\hline & 6 & 371,948 & $12,218,000$ & 62,567 & 47 & 32,878 & 66 \\
\hline & 10 & 32,273 & 270,000 & 6,625 & 56 & 3,618 & 75 \\
\hline & 11 & 555,419 & $7,400,000$ & 146,129 & 26 & 74,575 & 52 \\
\hline & & & & 215,321 & & 111,071 & \\
\hline \multicolumn{8}{|c|}{ Vesper Sparrow (Pooecetes gramineus) } \\
\hline & 5 & $2,778,377$ & 11,000 & 187,820 & 102 & 119,876 & 106 \\
\hline & 6 & 78,765 & $2,780,000$ & 13,030 & 40 & 8,258 & 45 \\
\hline & 8 & 25,025 & 93,200 & 5,529 & 161 & 3,536 & 169 \\
\hline & 9 & 7,066 & 300,000 & 1,554 & 93 & 987 & 86 \\
\hline & 10 & 28,707 & $1,100,000$ & 6,409 & 103 & 4,114 & 111 \\
\hline & 12 & 68,718 & 90,000 & 16,462 & 206 & 10,660 & 214 \\
\hline & 13 & 117,343 & 135,000 & 17,566 & 224 & 11,217 & 229 \\
\hline & 14 & 8,915 & 13,900 & 704 & 243 & 452 & 249 \\
\hline & & & & 249,074 & & 159,100 & \\
\hline \multicolumn{8}{|c|}{ Horned Lark (Eremophila alpestris) } \\
\hline & 6 & 231,365 & 347,000 & 17,185 & 102 & 5,392 & 102 \\
\hline & 8 & 12,648 & 140,000 & 630 & 150 & 198 & 150 \\
\hline & 11 & $1,248,795$ & $10,700,000$ & 107,429 & 256 & 33,712 & 39 \\
\hline & 12 & 8,464 & 9,800 & 477 & 119 & 150 & 119 \\
\hline & 13 & 230,438 & 240,000 & 11,780 & 139 & 3,697 & 139 \\
\hline & 14 & 352 & 2,440 & 23 & 126 & 7 & 129 \\
\hline & & & & 137,524 & & 43,156 & \\
\hline
\end{tabular}

Koslowsky (2011), there was a strong negative trend between hay production and grassland bird population among $85 \%$ of the grassland species they considered. However, speciesspecific effects are important considerations when evaluating the overall impact of a particular mechanical disturbance on avian wildlife; in some situations, species are not at all affected by intensive farming regimes (Bradbury et al. 2000, Horn and Koford 2000). Because some species are clearly not affected by hay cutting (e.g., Horned larks which complete their nest cycle before a first cut of hay), their apparent dependence on hay production still needs to be explained.

We have modeled the results of a single cutting, seeding, or tillage operation. Repeated hay cutting within the breeding season window or multiple tillage operations in the case of traditional fallow may increase overall bird losses. In Nova Scotia, for example, a second cut usually occurs six to eight 
weeks after the first cut (Bill Thomas, personal communication). It is therefore conceivable that both cuts might result in mortality but it is unlikely that both would coincide with the same nesting attempt. In case of repeated fallow operations or cultivation steps after seeding when the interval between the operations is shorter, e.g., repeated tillage operations to keep weeds down in a fallow field, considering a second mechanical operation would also likely increase our estimates. We did not consider renesting in this analysis because it would add another layer of complexity and uncertainty in the calculation and modeling process. Renesting rates can vary across species, geographic regions, and habitat types but may occur if losses due to mechanical operations are early in the season (e.g. for Bobolink, see Bollinger et al. 1990). Considering renesting in the model would increase total estimates of incidental take but, more importantly, it would reduce population level effects because losses of eggs and young during the first nesting attempt may be partly replaced with successfully fledged young from a second attempt. Considering a possibly lower mortality rate (currently $100 \%$ for the egg and prefledging stage for each simulated mechanical operation) would clearly reduce total estimates of incidental take.

Parameter uncertainty is also associated with our assumed population density estimates, which we needed to define for each BCR and agricultural habitat type within Canada. However, by constraining these numbers within population estimates from the PIF/BBS database (see Table 3 ) we believe that our total estimates for nests/eggs are reasonable and defensible for the purpose of this study: all of our total population estimates for agricultural habitat types considered in each BCR were below the PIF/BBS estimates that also include nonagricultural habitat.

Although many of these populations, especially in eastern Canada, may still be at elevated levels compared to presettlement, proper management of agricultural habitats is crucial if currently declining population trends, both in eastern and western Canada, are to be successfully reversed. Avian species currently relying on agricultural habitats for breeding and nesting would turn to nonagricultural grassland areas if those were available (Herkert 1997); however, there is a lack of protected areas, and this is unlikely to change given our food pressures for a growing human population. This highlights the importance of adopting mitigation approaches on currently cultivated lands.

Freemark and Kirk (2001) documented higher species richness, abundance, and population sizes in organic operations than in conventional agricultural sites and recommend shifts toward organic farming to mitigate the rapid decline of grassland species. In managed pastures and forage crops however, the timing of disturbances rather than inputs is likely the most critical factor (Perrit and Best 1989, Dale et al. 1997, McMaster et al. 2005). Delaying disturbances by small increments can significantly improve species productivity: a 1.5 week delay in hay cutting practices on Nova Scotia fields resulted in a $20 \%$ increase in fledging rates (Nocera et al. 2005); this was amply visible in our sensitivity analysis (Figure 4). Other authors recommend leaving some fields nonharvested each year, to provide appropriate habitat for those species requiring tall vegetation for nesting (e.g., Roth et al. 2005); this would also reduce the direct kill from mowing operations.

At this stage, our calculated mortalities should be considered rough estimates. It is most likely that these estimates are conservative, especially because repeat cutting operations have not been factored in, although this might be offset by renesting as discussed above. We did not extend our analysis to all affected species, nor did we address population level effects which, in the future, could help us to better understand the overall effects of agricultural mechanical operations on bird populations.

Although our estimates are subject to an unknown degree of uncertainty, we believe that this assessment is a very important first step. First, it provides wildlife managers with broad estimates of incidental take for a set of species that may be particularly vulnerable to mechanical operations, based on the best available knowledge. Second, our assessment provides a first important starting point for future refinements of model parameters if and when more data become available. Finally, many of the species covered in our analysis have been thoroughly studied over the last decades, including population demography, distribution, and abundance. If, at this stage, we are not able to utilize such a rich pool of biological knowledge then we will probably never be able to estimate the extent of incidental kill for all the other species utilizing agricultural regions across Canada.

Responses to this article can be read online at: http://www.ace-eco.org/issues/responses.php/559

\section{Acknowledgments:}

We are immensely grateful for the cooperation of $A A F C$ personnel, namely Steven K. Javorek and Matt Grant who were kind enough to supply us with their species ratings as well as with the agricultural habitat data recompiled by BCR that were used in our calculations. This work could not have proceeded without their assistance. We also acknowledge the contribution of Peter Blancher, Mike Cadman, Brenda Dale, Jim Devries, and Joe Nocera who initially commented on the species list and offered useful advice. Eric Butterworth and Michel Gendron provided literature, data, and comments. Two anonymous reviewers as well as Dave Duncan, Brenda Dale, 
Peter Joyce, Jamie Hewitt, Bob Clark, and Ray Alisauskas commented on previous drafts. Greg Robertson and Craig Machtans shepherded these reviews and offered useful comments of their own. Expert opinion on forage and haying from the following individuals is acknowledged: Chris Zabek (British Columbia); Arvid Aasen and Gordon Hutton (Alberta); Michel Tremblay (Saskatchewan); Bill Thomas (Nova Scotia), Joel Bagg (Ontario); Brian Beaton (PEI); Guy Hayart (Québec). Numerous other individuals from the relevant provincial ministries of agriculture helped us to identify the provincial forage experts. Erin Mutrie made the contacts and compiled the information. We finally would like to thank Eva Jenkins of Bird Studies Canada for supplying the map of BCR's in Canada.

\section{LITERATURE CITED}

Askins, R. A., F. Chávez-Ramírez, B. C. Dale, C. A. Haas, J. R. Herkert, F. L. Knopf, and P.D. Vickery. 2007. Conservation of grassland birds in North America: understanding ecological processes in different regions. Ornithological Monographs 64:1-46.

Banks, R. C. 1979. Human related mortality of birds in the United States. U.S. Fish and Wildlife Service, Special Scientific Report - Wildlife 215:1-16.

BirdLife International. 2004. Grassland birds are declining in North America. State of the world's birds. BirdLife International, Cambridge, UK. [online] URL: http://www. birdlife.org/datazone/sowb/casestudy/63

Blancher, P. J., K. V. Rosenberg, A. O. Panjabi, B. Altman, J. Bart, C. J. Beardmore, G. S. Butcher, D. Demarest, R. Dettmers, E. H. Dunn, W. Easton, W. C. Hunter, E. E. IñigoElias, D. N. Pashley, C. J. Ralph, T. D. Rich, C. M. Rustay, J. M. Ruth, and T. C. Will. 2007. Guide to the Partners in Flight population estimates database. Version: North American landbird conservation plan 2004. Partners in Flight Technical Series No 5. [online] URL: http://rmbo.org/pif db/laped/ download/Guide\%20to\%20PIF\%20Population\%20Estimates\% 20Database\%202.pdf

Bollinger, E., P. B. Bollinger, and T. A. Gavin. 1990. Effects of hay-cropping on eastern populations of the bobolink. Wildlife Society Bulletin 18:142-150.

Bradbury, R. B., A. Kyrkos, A. J. Morris, S. C. Clark, A. J. Perkins, and J. D. Wilson. 2000. Habitat associations and breeding success of Yellowhammers on lowland farmland. Journal of Applied Ecology 37:789-805. http://dx.doi. org/10.1046/j.1365-2664.2000.00552.x

Calverley, B., and T. Sankowski. 1995. Effectiveness of tractor-mounted flushing devices in reducing accidental mortality of upland-nesting ducks in Central Alberta hayfields. Alberta North American Waterfowl Management Plan Centre. NAWMP-019. Edmonton, Alberta, Canada.
Chamberlain, D. E., R. J. Fuller, R. G. H. Bunce, J. C. Duckworth, and M. Shrubb. 2000. Changes in the abundance of farmland birds in relation to the timing of agricultural intensification in England and Wales. Journal of Applied Ecology 37:771-788. http://dx.doi.org/10.1046/

j.1365-2664.2000.00548.x

Dale, B. C., P. A. Martin, and P. S. Taylor. 1997. Effects of hay management on grassland songbirds in Saskatchewan. Wildlife Society Bulletin 25:616-626.

Downes, C., P. Blancher, and B. Collins. 2011. Landbird trends in Canada, 1968-2006. Canadian Biodiversity: Ecosystem Status and Trends 2010, Technical Thematic Report No. 12. Canadian Councils of Resource Ministers. Ottawa, Ontario, Canada. [online] URL: http://www. speciesatrisk.ca/resource/DOCUMENT/7190No.12_Landbirds\% 20May\%202011 E.pdf

Erickson, W. P., G. D. Johnson, and D. P. Young, Jr. 2005. A summary and comparison of bird mortality from anthropogenic causes with emphasis on collisions. Pages 1029-1042 in C. J. Ralph and T. D. Rich, editors. Bird conservation implementation and integration in the Americas: proceedings of the Third International Partners in Flight Conference 2002. U.S. Forest Service, PSW-GTR-191, Albany, California, USA.

Faaborg, J., R. T. Holmes, A. D. Anders, K. L. Bildstein, K. M. Dugger, S. A. Gauthreaux, P. Heglund, K. A. Hobson, A. E. Jahn, D. H. Johnson, S. C. Latta, D. J. Levey, P. P. Marra, C. L. Merkord, E. Nol, S. I. Rothstein, T. W. Sherry, T. S. Sillett, F. R. Thompson, and N. Warnock. 2010. Conserving migratory land birds in the New World: do we know enough? Ecological Applications 20:398-418. http://dx.doi. org/10.1890/09-0397.1

Freemark, K. E., and D. A. Kirk. 2001. Birds on organic and conventional farms in Ontario: partitioning effects of habitat and practices on species composition and abundance. Biological Conservation 101:337-350. http://dx.doi.org/10.1016/ S0006-3207(01)00079-9

Giuliano, W. M., and S. E. Daves. 2002. Avian response to warm-season grass use in pasture and hayfield management. Biological Conservation 106:1-9. http://dx.doi.org/10.1016/ S0006-3207(01)00126-4

Green, R. E. 1996. Factors affecting the population density of the Corncrake Crex crex in Britain and Ireland. Journal of Applied Ecology 33:237-248. http://dx.doi.org/10.2307/2404746

Green, R. E., G. Rocamora, and N. Schäffer. 1997a. Populations, ecology and threats to the Corncrake Crex crex in Europe. Vogelwelt 118:117-134.

Green, R. E. , G. A. Tyler, T. J. Stowe, and A. V. Newton. 1997b. A simulation model of the effect of mowing of agricultural grassland on the breeding success of the 
Corncrake (Crex crex). Journal of Zoology 243:81-115. http:// dx.doi.org/10.1111/j.1469-7998.1997.tb05758.x

Grüebler, M. U., H. Schuler, P. Horch, and R. Spaar. 2012. The effectiveness of conservation measures to enhance nest survival in a meadow bird suffering from anthropogenic nest loss. Biological Conservation 146:197-203. http://dx.doi. org/10.1016/j.biocon.2011.12.019

Grüebler, M. U., H. Schuler, M. Müller, R. Spaar, P. Horch, and B. Naef-Daenzer. 2008. Female biased mortality caused by anthropogenic nest loss contributes to population decline and adult sex ratio of a meadow bird. Biological Conservation 141:3040-3049. http://dx.doi.org/10.1016/j.biocon.2008.09.008

Hannah, L., J. L. Carr, and A. Lankerani. 1995. Human disturbance and natural habitat: a biome level analysis of a global data set. Biodiversity \& Conservation 4:128-155. http:// dx.doi.org/10.1007/BF00137781

Herkert, J. R. 1994. The effects of habitat fragmentation on Midwestern grassland bird communities. Ecological Applications 4:461-471. http://dx.doi.org/10.2307/1941950

Herkert, J. R. 1997. Bobolink Dolichonyz oryzivorus population decline in agricultural landscapes in the Midwestern USA. Biological Conservation 80:107-112. http://dx.doi.org/10.1016/S0006-3207(96)00066-3

Hoekman, S. T., T. S. Gabor, R. Maher, H. R. Murkin, and M. S. Lindberg. 2006. Demographics of breeding female mallards in Southern Ontario, Canada. Journal of Wildlife Management 70:111-120. http://dx.doi.org/10.2193/0022-541X(2006)70 [111:DOBFMI]2.0.CO;2

Horn, D. J., and R. R. Koford. 2000. Relation of grassland bird abundance to mowing of Conservation Reserve Program fields in North Dakota. Wildlife Society Bulletin 28:653-659.

Humbert, J. Y., J. Ghazoul, and T. Walter. 2009. Meadow harvesting techniques and their impacts on field fauna. Agriculture, Ecosystems \& Environment 130:1-8 http://dx.doi. org/10.1016/j.agee.2008.11.014

Jobin, B., L. Bélanger, C. Boutin, and C. Maisonneuve. 2004. Conservation value of agricultural riparian strips in the Boyer River watershed, Québec (Canada). Agriculture, Ecosystems \& Environment 103:413-423. http://dx.doi.org/10.1016/j. agee.2003.12.014

Kennedy, J. A., P. Dilworth-Christie, and A. J. Erskine. 1999. The Canadian breeding bird (mapping) census database. Technical Report Series No. 342, Canadian Wildlife Service, Ottawa, Ontario, Canada. [online] URL: http://dsp-psd. pwgsc.gc.ca/Collection/CW69-5-342E.pdf

McCracken, J. D. 2005. Where the Bobolinks roam: the plight of North America's grassland birds. Biodiversity 6:20-29. http://dx.doi.org/10.1080/14888386.2005.9712771
McLaughlin, A., and P. Mineau. 1995. The impact of agricultural practices on biodiversity. Agriculture, Ecosystems \& Environment 55:201-212. http://dx.doi.org/10.1016/0167-8809 (95)00609-V

McMaster, D. G., J. H. Devries, and S. K. Davis. 2005. Grassland birds nesting in haylands of southern Saskatchewan: landscape influences and conservation priorities. Journal of Wildlife Management 69:211-221. http:// dx.doi.org/10.2193/0022-541X(2005)069<0211:GBNIHO>2.0. $\mathrm{CO} ; 2$

Mineau, P., and A. McLaughlin. 1996. Conservation of biodiversity within Canadian agricultural landscapes: integrating habitat for wildlife. Journal of Agricultural and Environmental Ethics 9(2):93-113. http://dx.doi.org/10.1007/ BF03055296

Müller, M., R. Spaar, L. Schifferli, and L. Jenni. 2005. Effects of changes in farming of subalpine meadows on a grassland bird, the Whinchat (Saxicola rubetra). Journal of Ornithology 146:14-23. http://dx.doi.org/10.1007/s10336-004-0059-0

Newton, I. 1998. Bird Conservation problems resulting From agricultural intensification in Europe. Pages 307-322 in J. Marzluff and R. Sallabanks, editors. Avian conservation, research and management. Island Press, Washington, D.C., USA.

Nocera, J. J., G. Forbes, and G. R. Milton. 2007. Habitat relationships of three grassland breeding bird species: broadscale comparisons and hayfield management implications. Avian Conservation and Ecology 2(1): 7. [online] URL: http:// www.ace-eco.org/vol2/iss 1/art7

Nocera, J. J., and H. M. Koslowsky. 2011. Population trends of grassland birds in North America are linked to the prevalence of an agricultural epizootic in Europe. Proceedings of the National Academy of Science 108:5122-5126. http://dx. doi.org/10.1073/pnas.1018904108

Nocera, J. J., G. J. Parsons, G. R. Milton, and A. H. Fredeen. 2005. Compatibility of delayed cutting regime with bird breeding and hay nutritional quality. Agriculture, Ecosystems \& Environment 107:245-253. http://dx.doi.org/10.1016/j. agee.2004.11.001

Norment, C. J., M. C. Runge, and M. R. Morgan. 2010. Breeding biology of grassland birds in western New York: conservation and management implications. Avian Conservation and Ecology 5(2): 3. http://dx.doi.org/10.5751/ACE-00399-050203

Patterson, M. P., and L. B. Best. 1996. Bird abundance and nesting success in Iowa CRP fields: the importance of vegetation structure and composition. American Midland Naturalist 135:153-167. http://dx.doi.org/10.2307/2426881 
Perlut, N. G., A. M. Strong, T. M. Donovan, and N. J. Buckley. 2006. Grassland songbirds in a dynamic management landscape: behavioral responses and management strategies. Ecological Applications 16:2235-2247. http://dx.doi. org/10.1890/1051-0761(2006)016[2235:GSIADM]2.0.CO;2

Perritt, J. E., and L. B. Best. 1989. Effects of weather on the breeding ecology of Vesper Sparrows in Iowa crop fields. American Midland Naturalist 121:355-360. http://dx.doi. org/10.2307/2426040

Roth, A. M., D. W. Sample, C. A. Ribic, L. Paine, D. J. Undersander, and G. A. Bartelt. 2005. Grassland bird response to harvesting switchgrass as a biomass energy crop. Biomass and Bioenergy 28:490-498. http://dx.doi.org/10.1016/j. biombioe.2004.11.001

Saumure, R. A., T. B. Herman, and R. D. Titman. 2007. Effects of haying and agricultural practices on a declining species: the North American wood turtle, Glyptemys insculpta. Biological Conservation 135:565-575. http://dx.doi.org/10.1016/j.

biocon.2006.11.003

Seigel, A. B., and J. L. Lockwood. 2010. How increasing levels of private land enrollment in conservation agreements affect the population viability of grassland birds. Biodiversity and Conservation 19:2343-2357. http://dx.doi.org/10.1007/

s10531-010-9837-6

Shustack, D. P., A. M. Strong, and T. M. Donovan. 2010. Habitat use patterns of Bobolinks and Savannah Sparrows in the northeastern United States. Avian Conservation and Ecology 5(2): 11. http://dx.doi.org/10.5751/ACE-00423-050211

Tilman, D., J. Fargione, B. Wolff, C. D’Antonio, A. Dobson, R. Howarth, D. Schindler, W. H. Schlesinger, D. Simberloff, and D. Swackhammer. 2001. Forecasting agriculturally driven global environmental change. Science 292:281-284. http://dx. doi.org/10.1126/science.1057544

Warner, R. E., and S. L. Etter. 1989. Hay cutting and the survival of pheasants: a long-term perspective. Journal of Wildlife Management 53:455-461. http://dx.doi.org/10.2307/3801150

Winter, M., D. H. Johnson, J. A. Shaffer, and W. D. Svedarsky. 2004. Nesting biology of three grassland passerines in the northern tallgrass prairie. Wilson Bulletin 116:211-223. http:// dx.doi.org/10.1676/03-082 
Appendix 1. Electronic Appendix

Please click here to download file 'appendix1.xls'. 


\section{APPENDIX 2}

\section{Approach for Estimating Agricultural Mortality (example Bobolink)}

\section{Background Data and Preliminary Calculations for Bobolink}

1. Background species data required from literature:

a. adult population density as \# adults $/ \mathrm{km}^{2}$ (as per literature review)

b. mean clutch size (as per Peck and James 1987)

c. range of daily survival rates (DSRs) from literature sources

d. range of recorded egg dates (from Peck and James 1987)

e. within-year (intra-annual) egg laying date variation from literature sources

f. mean incubation and nestling period (from Ehrlich et al. 1988)

* assumes $100 \%$ young fledge this number of days after laying

g. within-year fledging date variation from literature sources

* this should theoretically be consistent with estimates for $1 \mathrm{e}$

h. number of broods per year (from Peck and James1987, Ehrlich et al. 1988)

* to date, 1 brood and no re-nesting have been assumed

i. For waterfowl species only, adult mortality due to AG events from literature

2. Background agriculture data*:
a. number of cuts
b. possible first cut dates

* both as per expert opinion and literature sources where possible

3. Develop regression model for predicting the portion of eggs laid by a given date

Use data on within-year egg laying date variation (line 1e) obtained from the literature to develop a regression equation to predict the percentage of total eggs laid in a year that will be laid by $\mathrm{X}$ number of days into the laying period.

4. Develop regression model to predict the portion of young fledged by a given date Use data on within-year fledging date variation (line $1 \mathrm{~g}$ ) obtained from the literature to develop a regression equation to predict the percentage of total young that will have fledged (i.e., have left the nest) by $\mathrm{X}$ days into the fledging period.

5. Determine the amount $\left(\mathrm{km}^{2}\right)$ of a given agricultural habitat type within the region This component has been estimated using the NAHARP database.

6. Calculate possible first dates for egg laying.

The first possible date is the first egg date as determined in the background data (line 1d). The last possible date for the onset of egg laying is equal to the last recorded egg date (line 1d) minus the within-year laying date variation (line 1e), given that all egg laying must have been completed in any given year by the last egg date.

7. Calculate possible first dates for fledging

First dates of fledging are equal to the possible first dates for egg laying (line 6) plus the mean incubation and nestling period (line 1f).

8. Calculate adult population size 
This is equal to density (line 1a) multiplied by area (line 5).

9. Calculate the total number of nests

Total number of nests is calculated as the adult population size (line 7) divided by 2 , assuming a 1:1 sex ratio and 1 nest per adult female.

10. Calculate the total number of eggs

The total number of eggs equals the total number of nests (line 8) multiplied by mean clutch size (line 1b).

\section{Simulations}

11. Generate first date of egg laying randomly

For first day of egg laying a uniform distribution was used, with a range of dates equal to those determined as possible first egg laying dates (line 6). All dates within that range had the same probability of being selected; randomly generated values are rounded to whole numbers.

12. Determine last day of egg laying

The last day of egg laying is equal to the first egg laying day selected (line 11) plus the within-year egg laying variation period (line 1e).

13. Determine the first day of fledging

Calculated as the first day of egg laying (line 11) plus the mean incubation and nestling period (line 1f).

14. Determine the last day of fledging

Calculated as the first day of fledging (line 13) plus the within-year fledging date variation (line 1g).

15. Determine DSR

Determined using a uniform distribution of the range of DSRs reported in the literature for that species (line 1c)

16. Generate the cut day

The selected cut date is determined relative to the first egg laying date (line 11) because of an assumed correlation based on weather dependence within a given year. To account for this correlation, the possible first egg laying dates / cut dates were divided into thirds (the use of thirds specifically is ad hoc); if the randomly selected first day of egg laying (line 11) is in the 1st third of possible egg laying dates, the cut will be randomly selected within the first third of possible cut dates and so forth. This method allows for the correlation between the two parameters, while maintaining a degree of variability.

17. Determine if the cut occurred during the laying period

If the cut occurred after the first day of egg laying and before the last day of egg laying the Boolean values for each of these two intermediate steps will both be true (each with a value of 1), and thus the cut did occur during laying and the value for this parameter will also be true (with a value of 1 ). If either of these statements is false, it will be given a value of 0 indicating that the cut did not occur during laying. 
18. Calculate the number of days into egg laying that the cut occurred

Calculated as cut day (line 16) minus first day of egg laying (line 11). Negative values indicate that the cut occurred before any laying began.

19. Apply the "egg" regression model

The regression model predicting the percentage of eggs laid by day $X$ (line 3 ) is applied with $X$ being the number of days into the laying period that the cut occurred. Model output is multiplied by the value of line 17 (if the cut occurred during laying) If the cut did occur during laying, model output is multiplied by 1 , resulting in a final value equal to regression model output. If the cut did not occur during laying, the model output is multiplied by 0 , resulting in null values. Depending on the nature of the regression model, intermediate steps may be required either prior to (e.g. creation of quadratic or interaction terms) or following its application (e.g. data transformation)

20. Determine the percentage of eggs laid by the cut date

This step will result in values equal to those in line 29, except in cases where all laying was complete before the cut occurred. In these situations, null values in line 29 (present because the cut did not occur during the laying period, but after it) will be changed to $100 \%$ given that all eggs will have been laid by the end of the laying period. Exact methods to derive this parameter from the regression model will vary depending on the nature of the data on which the regression model was developed.

21. Calculate the total number of eggs laid by the cut date

Calculated as the total number of eggs (line 10) multiplied by the percentage of eggs laid by the cut date (line 20).

22. Determine if the cut occurred during the fledging period

If the cut occurred after the first day of fledging and before the last day of fledging the Boolean values for each of these two intermediate steps will both be true (each with a value of 1), and thus the cut did occur during fledging and the value for this parameter will also be true (with a value of 1). If either of these statements is false, it will be given a value of 0 indicating that the cut did not occur during fledging.

23. Calculate the number of days into fledging that the cut occurred

Calculated as cut day (line 16) minus first fledging day (line 13). Negative values indicate that the cut occurred before any fledging began.

24. Apply the "fledge" regression model

The regression model predicting the percentage of young fledged by day $X$ (line 4 ) is applied with $X$ being the number of days into the fledging period that the cut occurred. Model output is multiplied by the value of line 22 (if the cut occurred during fledging) If the cut did occur during fledging, model output is multiplied by 1 , resulting in a final value equal to regression model output. If the cut did not occur during fledging, the model output is multiplied by 0 , resulting in null values. Depending on the nature of the regression model, intermediate steps may be required either prior to (e.g. creation of quadratic or interaction terms) or following its application (e.g. data transformation)

25. Determine the percentage of young already fledged by the cut date If the cut was during laying, but not during fledging the value in this column will be 0 , otherwise the value will be equal to that of the regression model application. A value of 1 indicates that the cut was not during laying or fledging. Exact methods to derive this 
parameter from the regression model will vary depending on the nature of the data on which the regression model was developed.

26. Calculate the total number of young fledged by the cut date

Calculated as the total number of eggs (line 10) multiplied by the percentage of young fledged by the cut date (line 25). This parameter accounts for young that have already left the nest by the cut date, and thus are not at risk of mortality by mechanical farming operations.

27. Calculate the percent of young in the nest at the time of the cut

Calculated as the percent of eggs laid by the cut date (line 20) less the percent of young already fledged by cut date (line 25). Negative values indicate that the cut occurred prior to any laying.

28. Calculate the number of young in the nest for the cut, no natural mortality

Calculated as the number of eggs laid by the cut date (line 21) multiplied by the percent in the nest at the time of the cut (line 27)

29. Calculate the median survival rate

The median nest day is equal to the incubation and nestling period (line 1f) minus one (since it is assumed all young have fledge on the last day), then divided by two. The median survival rate is calculated as the DSR to the power of the median nest day, and is equivalent to the percentage of young that could be expected to survive to the median nest day before the cut. This step assumes that laying occurs at a constant rate during the time (equal to incubation and nestling period) leading up to the cut.

30. Calculate the number of young in the nest at the cut date

Calculated as the median survival rate (line 29) multiplied by the number of young in the nest for the cut, no natural mortality (line 28).

31. Calculate natural survival rate

Calculated as the DSR (line 15) to the power of incubation and nestling period (line 1f) 1 (since all surviving young fledge on the last day of the nesting period).

32. Calculate the number of young lost at the cut

The total number of young killed (i.e. gross incidental take). Equal to the number of young in the nest at the cut date (line 30 ) given the assumption that all young in the nest will be killed.

33. Calculate the total number dead with the cut

Equal to the number of young in the nest for the cut, no natural mortality (line 28) given that all of these young either died naturally or were killed during the cut.

34. Calculate the total number dead without the cut

Calculated as the number of young in the nest for the cut, no natural mortality (line 28) multiplied by 1 less the natural survival rate (line 31 ) to effectively generate a natural death rate.

35. Calculate the additional number of young lost 
The number of young lost due to mechanical operations that would have been expected to survive in the absence of the cut. Calculated as the total number dead with cut (line 33) less the total number dead without the cut (line 34).

36. Calculate mortality increase

The rate of increase in mortality with the AG event over expected natural mortality rates. Calculated as the total number dead with the cut (line 33) divided by total number dead without the cut (line 34). A value of 1 indicates no increase in mortality.

37. For waterfowl species only: determine if the cut occurred during laying or fledging If the Boolean value of lines 17 and/or 22 are 1 (e.g. cut did occur during laying and/or fledging) a Boolean value of 1 is used for this parameter as well. A value of 0 indicates the cut occurred either prior to any laying or after all fledging.

38. For waterfowl species only: calculate number of adults killed

Calculated as percentage adult mortality (line 1e) multiplied by the adult population size (line 8) multiplied by the Boolean value in line 37 (i.e. if the cut did not occur during laying or fledging this results in 0 adult mortality).

39. Repeat above procedure (lines 11-36 inclusive, lines 11- 38 for waterfowl species) 100 times. Calculate the mean (+/- standard deviation) of number of young (and adults for waterfowl species) lost at the cut (line 32), and additional number of young lost (line 35). 